\title{
El giro estético: epistemología de frontera ${ }^{1}$ \\ The Aesthetic Turn: Border Epistemology \\ O giro estético: epistemologia de fronteira
}

Carlos E. Valenzuela ${ }^{2}$

Resumen

El presente artículo da cuenta de una lectura que apenas si otea, por decirlo menos, el carácter de aquel giro que diversos filósofos, de Nietzche a Welsch, pasando por Goodman y Ortega y Gasset, han inspirado. Me refiero al giro estético, desplazamiento epistémico que ha persuadido a la ciencia de refrendar en su propio seno la importancia de la creatividad, la metaforización y la estetización como variables a tener en cuenta en todo proceso de conocimiento. De allí que dicho giro merezca ser puesto de relieve, dada la centralidad que se le concede en relación con nuestras maneras de concebir la realidad y apreciar el conocimiento.

Palabras clave

Estético, giros, epistemología, realidad, conocimiento, ciencia

Abstract

This article reports on a reading that, to say the least, just peers into the character of that turn which several philosophers, from Nietzsche to Welsh passing by Goodman and Ortega y Gasset, have inspired. I refer to the aesthetic turn, an epistemic move that has persuaded science of renovating within itself the importance of creativity, metaphorization and aestheticization as variables to be taken into account in any knowledge process. That is why this very turn deserves an emphasis, given the centrality it is given as to our ways of conceiving reality and appreciating knowledge.

Keywords

Aesthetics, turns, epistemology, reality, knowledge, science

Resumo

0 presente artigo apresenta uma leitura que apenas mostra, por assim dizer, o caráter de aquele giro que inspiraram vários filósofos, desde Nietzche até Welsh, passando por Goodman e Ortega y Gasset. É dizer, o giro estético, deslocamento epistêmico que persuadiu à ciência para referendar em seu próprio seio a importância da criatividade, a metaforização e a estetização como variáveis para levar em conta durante todo processo de conhecimento. Por isso esse giro merece ser ressaltado devido à centralidade que tem em relação com nossas maneiras de conceber a realidade e apreciar o conhecimento.

\section{Palavras chave}

Estético, giros, epistemologia, realidade conhecimento, ciência

Artículo recibido el 21 de abril de 2016 y aprobado el 5 de agosto de 2016

1 El presente artículo de reflexión fue realizado en el marco del seminario doctoral "Narrativas Docentes y Discurso Pedagógico" del Doctorado Interinstitucional en Educación de la Universidad Pedagógica Nacional, del cual soy estudiante.

2 Magíster en Estudios Sociales, docente de la Universidad Pedagógica Nacional, Bogotá, Colombia. Correo electrónico: duardoco@yahoo.com 


\section{Introducción}

Este artículo no pretende ser ni mucho menos una diatriba respecto del modo de pensar que la ciencia blandió a lo largo del siglo xix y parte del xx; lógica cuya manera de operar, he de reconocerlo, a veces añoro en virtud de aquellas laxas prerrogativas que el razonar de esta época parece conferirle al científico social. Más que de epistemología, hoy tendría más sentido hablar de logias epistémicas cuyo advenimiento, -iqué paradoja!- pareciese obedecer más al deceso de la razón que a su florecimiento, pues es evidente cómo hemos empezado a tomar distancia de ella en los claustros universitarios, relegándola a prácticas mal llamadas academicistas, "cada vez más en retirada o embolsadas en rituales dignos de círculos iniciados” (Cruz Kronfly, 2007). ¿Acaso no señalan hoy por hoy muchos profesores que la teorización va en detrimento de los intereses del estudiantado? Aún más, que ¿para qué tanta teoría? No es, pues, ese el espíritu que alienta esta escritura; y hago tal salvedad en virtud del tema más bien heterodoxo sobre el que versa este artículo: el giro estético.

Uno sobre el que diserto con ínfulas de exegeta pues lo que hago es revisar y exponer básicamente lo dicho por Bermejo (2008) a propósito de un movimiento epistémico al que distintos autores le atribuyen la responsabilidad de haber suscitado todo un cambio de paradigma en relación con la figura del saber y su naturaleza.

En ese orden de ideas, comienzo por dejar entrever el contexto de discusión sobre el que se afincan mis apreciaciones generales respecto del giro estético. Luego, introduzco el asunto de los giros, aquellos que, aunados al estético, inauguran a lo largo del siglo xx una manera distinta de asumir el conocimiento por cuanto le asignan un estatuto diferente al declarado por la modernidad. Finalmente, al cabo de un par de breves disquisiciones en torno del construccionismo social y su incidencia en los principios defendidos por el triple giro epistémico, cierro el artículo evidenciando el peso del giro estético en nuestras formas de conocer y aprehender el mundo.

\section{Ángulo de lectura adoptado}

Cuando me propuse escribir estas líneas tuve dudas respecto del carácter que finalmente le atribuiría al texto. Y no porque considerase que el género del ensayo, representante inequívoco del discurso de la razón, no fuese oportuno en virtud de que patenta, a propósito del desencanto por el saber, un "academicismo" para muchos recalcitrante. La verdad, preferí que la cuestión se dirimiese directamente en el papel dado que, si bien en principio estaba convencido de producir un documento respetuoso de los cánones, después de ahondar en las fuentes de consulta concernientes a lo que Welsch y otros han dado en llamar giro estético, concluí que algo tan ortodoxo como lo que pretendía hacer en un inicio quizá no sería del todo procedente o, digamos, "políticamente correcto".

Y esto lo constaté con claridad al notar cómo, al cabo de mis lecturas de referencia, me embargó el impulso de acudir sin pestañear a Borges, con la esperanza de extraer para el encabezado de mi escrito un verso que, habida cuenta del tono y carácter de las lecturas previas, habría sido sin duda el epígrafe perfecto. Pero, escéptico un poco ya, más por experiencia que por dogma, de aunar versos con proposiciones, elegí obviar esta vez al literato argentino.

Así las cosas, lo que ahora ofrezco es un texto que no por inclasificable carece de pauta y medida, pues, si algo cabe aprehender en torno del relativismo descrito por el giro epistémico del cual hablaré aquí, es justamente a no caer en la arbitrariedad, eso de lo que lo acusan (al giro) precisamente quienes ven en él un juego de veleidades y desvaríos, la antípoda - podría decirse- del fundacionalismo moderno (Taylor, 1997).

Y con esto último que señalo ya voy dando apertura al tema del artículo: el giro estético, aquel cuyo énfasis acentúa en especial la condición creativa y performativa del ser hablante. Pero, antes de encarar el tema en cuestión con no mucha exhaustividad, dadas las condiciones de espacio, creo que es necesario hablar acerca del contexto de discusión 
sobre el que dicho tema se sitúa, y este no es otro que el de la epistemología, es decir, la auditora de la ciencia. Es aquí, en efecto, donde, al menos en primera instancia, adquiere sentido hablar sobre giros, mutaciones, bucles, vuelcos y revoluciones con relación al estatuto del conocimiento y la realidad.

Así pues, es la pregunta por el conocimiento y la relación que con él establecemos la que nos impele a hablar de giros; giros que aluden a las transformaciones acaecidas en el siglo xx sobre la manera clásica que nos legó la ciencia moderna de ver el mundo; aquel que se nos patrocinó como "el" mundo; uno al que se accedía a expensas del sujeto o prescindiendo de él como obstáculo, lo cual, señalémoslo de paso, resultaba completamente consecuente desde un punto de vista para el que el oficio de la investigación científica no puede obedecer sino a las reglas de la gramática que le concierne, hecha a base de algoritmos y presupuestos que, en la medida en que más se alejan del parecer subjetivo del investigador de turno, más se acercan al prurito científico de las disciplinas.

Esta manera de proceder, pues, objetiva, determinista, neutral, en fin, se reificó al grado de hacernos creer que no era simplemente una manera, sino"la" manera más expedita de conocer la realidad, una en principio inescrutable, excepto para el ojo del científico cuyo conocimiento de esta espetaba, confiado en que guardase cierto isomorfismo con la "cosa" misma allí situada, afuera, a distancia del observador. Distancia que la tradición epistemológica aún pontifica y vela porque se tenga presente al instante de configurar los objetos de los que las disciplinas se hacen cargo, situándolos al margen de las prenociones que derivan de ese sentir indiferenciado desde el que el común de las personas percibe el mundo. Vigilancia que para muchos no puede dejar de operar en la ciencia, so pena de tornarla otra cosa distinta a aquella que fundó la modernidad, basándose en el dualismo sujeto-objeto que marcó de forma perentoria el quehacer del científico cuya fe, si se me permite el término, por muchos años se amparó en el ideario cartesiano de la escisión, de acuerdo con el cual nuestras ideas no son más que imágenes, que fácilmente pueden ser imitaciones imperfectas de las cosas.
De tal postura filosófica la tradición epistémica ha extraído una serie de principios rectores con los que la ciencia no ha dudado en comulgar de modo irrestricto durante siglos, sin advertir cómo, al margen de ese cauce de elucubración racionalista, flanqueada por el poder de la conciencia y el logicismo matemático, han brotado otras corrientes de pensamiento, reivindicativas de la amalgama y la conjunción entre razón y sensación; entre sujeto y objeto, leídos convencionalmente desde el tamiz de la disyunción y la criba de la simplificación.

Justamente, son estos principios epistemológicos los que entran a poner en tela de juicio los giros lingüístico, pragmático y estético al esgrimir, mutatis mutandis, que la realidad no existe con independencia del sujeto, su palabra y su historia. Es momento entonces, ahora sí, de profundizar un poco en las connotaciones de tal tesis y recoger las implicancias de lo señalado específicamente por el giro estético en relación con la tarea de conocer y aprehender el mundo.

\section{Sobre los giros}

Aseverar con mayúscula eso de que la realidad no existe resulta indigerible mientras no se explicite el lugar de enunciación desde el cual se hace la afirmación. Y este lugar es el del relativismo, aquel para el cual la realidad no es "algo" ubicado allí afuera, con independencia del que la observa y la describe como nos lo enseñó diligentemente la tradición occidental. Por el contrario, es esta una creación que, afín con la tesis defendida por el giro lingüístico, emerge en virtud de lo que decimos acerca de ella, dado que la realidad es realidad en virtud del lenguaje que la esculpe, pues, recordemos:

... el lenguaje no es mero instrumento o mediación entre el conocimiento y la realidad. Las proposiciones no son ni expresión de una conciencia pura que descubre las estructuras a priori de las cosas - mito de la conciencia y de la lógica (Wittgenstein, Davidson, Rorty)- ni representación pura de las estructuras objetivas de una naturaleza independiente -mito de la objetividad de la ciencia física y de lo dado (Sellars, Quine)-. La realidad es siempre realidad descrita o interpretada y las estructuras racionales son estructuras lingüísticas, 
insertas en un sistema semiótico y simbólico. (Wittgenstein, Rorty, Goodman, Vattimo) (Bermejo, 2008, p. 52)

Decir cosas produce cosas; la palabra en tal medida es inaugural, diríamos, constitutiva; el gesto insufla sentido; el discurso crea, da lugar a la existencia, a una existencia, por supuesto, revestida por el carácter contextual, social y cultural del que la nombra, lo que equivale a reconocer, de acuerdo con lo estipulado por el giro pragmático, que no hay proposición divorciada de intereses, inmediatos o mediatos; históricos o ideológicos; todo enunciado encierra ulteriores pretensiones que le hacen único, situado, dependiente de un contexto social específico, en el seno del cual y a propósito del cual adquiere validez, de acuerdo con las reglas allí estipuladas, pues no existe escritura o enunciado, de acuerdo con presupuestos derridianos, que no esté condenado a naufragar en el vacío oceánico de la indeterminación, del que la palabra busca en vano desasirse una y otra vez pese al precipicio de sentidos que le espera del otro lado.

El lenguaje [...] posee la cualidad de identificar, de concretar, es arbitrario y convencional, pero también crea mundos y modela conciencias: aprisiona al nombre entre sus bordes, y a su vez, los trasciende... Su carácter inasible nos atrapa conforme se escapa dejando al lector en la incertidumbre de su significado. Nos aproximamos siempre a las palabras, mas nunca alcanzamos a aprehenderlas por completo debido a su afán de disolverse. (Hamui Sutton, 2014, p. 137)

Estas consideraciones derivadas de lo señalado por los giros lingüístico y pragmático hacen de la realidad, al menos aquella entendida en términos de un absoluto o puro dado, una idea proscrita para los partidarios del antirrealismo, quienes, en concordancia con el giro estético, declaran "el carácter ficcional o construido de la realidad, la ausencia de fundamento único y último, y la legitimidad de la pluralidad en tanto estructura constituyente tanto de la razón como de la realidad" (Bermejo, 2008, p. 53).

Aseveraciones de tal índole respecto del conocimiento, la realidad y su estatuto constituirán la obertura de lo que se erigirá como la plataforma propicia para escenificar los alcances del triple giro epistémico.Hablamos del posestructuralismo, corriente capaz de "acoger la incertidumbre de los significados, el poder constitutivo del discurso y la efectividad política de la teoría y la investigación" (Gibson-Graham, 2002, p. 261). Principios que cabría entrar a revisar con mayor detenimiento por cuanto impelen a dudar respecto de la unidad que ha reportado para nosotros la realidad desde siempre, vista como un mundo descubierto y no engendrado; dispuesto, no puesto; existente, no creado; evangelio este de certezas al que nos hemos plegado con cierto convencimiento debido a que, pese a lo doctrinario de la afirmación, nos ha permitido asirnos de un referente hecho a base, no obstante, de imaginación, así le consideremos al cabo del tiempo, de acuerdo con Nietzsche, natural o preexistente.

Ahondemos ahora, vía el construccionismo social, en aquello del carácter construido de la realidad, antes de entrar a hablar finalmente acerca de las implicancias de tal planteamiento defendido por el giro estético.

\section{Onto-herejías posmodernas}

Previamente a las declaraciones que puedan darse respecto del estatuto moderno de realidad, el cual es puesto en tensión por un grueso y nutrido conjunto de planteamientos posestructuralistas que detentan casi al unísono la idea de acuerdo con la cual no hay realidad que nos trascienda, o determine en términos absolutos, considero importante esclarecer el carácter de la disputa que históricamente se ha casado entre quienes conceden peso ontológico a la realidad (realistas) y quienes se lo restan (antirrealistas). Y es hacia tal dirección hacia donde apuntan las precisiones que recojo de Tomas Ibáñez (2002). Veamos.

Pese a las diferencias milenarias tejidas entre quienes creen en la realidad y quienes dudan de ella, en un aspecto parecen darse la mano unos y otros, de acuerdo con Ibáñez (2002), y es en el asunto del ser o la problemática de la existencia. Efectivamente, hasta para el más férreo antirrealista resultaría descabellado 
ignorar que "algo", no se sabe a ciencia cierta qué, existe; y eso que existe, es decir, dicho "ser" precede al conocimiento del ser, de no ser así, no habría conocimiento del que hablar, pues, el conocimiento es "siempre conocimiento de algo" (p.19).

Por esta vía se llega al acuerdo de que el ser existe, en efecto, pero decir que el ser existe no equivale a decir que "la realidad" existe puesto que cuando se habla de realidad, se habla es de una versión del ser o de un cierto tipo de existencia al que le conferimos rasgos, cualidades, fisonomía, cara, voz, etc. Esta manera de concebir la realidad hace que le adjudiquemos, sin saberlo, estatuto de existencia a una modalidad, entre otras, de interpretación; interpretación que al cristalizarse adquiere densidad ontológica, es decir, olvidamos que la inventamos y la creemos "real". Al considerarla existente, única e independiente, dicha realidad se nos revela ajena, refractaria y absoluta. Se reifica y, en consecuencia, nos plegamos a su existencia, sin dudar de ella, sin cuestionar su particular configuración, a la que creemos "debernos" cuando, según señalan los antirrealistas, es la realidad la que se debe a nosotros, a lo que somos, a nuestras interpretaciones. Es por ello que concluyen los antirrealistas:

... no se puede hablar de la realidad fuera de las interpretaciones, la realidad es siempre ya realidad interpretada y todo lo que se puede decir de la realidad son redescripciones, no representaciones de un supuesto mundo en sí, exterior y fijado en sus contenidos, que espera a ser descubierto, al que hubiera que corresponder con reproducciones adecuadas y que pudiera ofrecer el criterio para determinar la exactitud de nuestras concepciones. La realidad no se encuentra, se construye. El contenido de la realidad es lingüístico, porque nuestro acceso a la realidad es lingüístico, nunca directo. Nuestro universo consistiría más bien en modos de descripción que en mundo o mundos literalmente entendidos. (Bermejo, 2008, p. 16)

De acuerdo con lo anterior, no habría en consecuencia realidad perse, es decir, preexistente a la mirada. Su estatuto sería otro, distinto al descrito por el realismo ontológico, para el que las características de la realidad "son las que son, las observemos o no, las conozcamos o no, tanto si existimos nosotros mismos como si no" (Ibáñez, 2002, p. 19). Este último postulado, de cariz completamente moderno, va a ser de hecho el que controvertirá el giro estético al compartir la idea de cuño posmoderno según la cual la realidad es contingente, plural y compleja. Cualidades que la ubican en un terreno epistémico móvil, cuya plasticidad difiere del estatismo al que la condenaba el paradigma del signo, ese puesto en tela de juicio por las corrientes poscientistas, imbuidas fuertemente por el influjo de los giros en general y del estético en particular.

\section{El giro estético: reflexiones liminares}

Allí situados, los giros, y en especial el estético, harán manifiesto el carácter constructivo de la realidad, hecha a base de lenguaje, no solo verbal, sino también de otros órdenes. Considerar en consecuencia que la realidad es objeto de factura, desestabiliza el credo cientista para el que ese absoluto con el que apellidaban a la realidad se desvanece, dando cabida a la posibilidad de fundar mundo o, como diría Goodman, versiones-mundo, cada cual adscrita a una peculiar cosmovisión de realidad. No habrían, por tanto, por esta vía, hechos constatables que no estuviesen precedidos o, mejor sería decir, "decididos" por una interpretación, responsable esta de hacerlos consistir.

¿Y qué interpretación ponderar de "mejor", dada la inexistencia de fundamento alguno sobre el que contrastar las propuestas interpretativas hechas? No habría manera de medir con arreglo a un mismo patrón de veridicción la justeza de las versiones, pues, de un lado, resultan inconmensurables entre sí y, de otro, no existe patrón fundacional a partir del cual dirimir la cuestión. Cada cual, por tanto, se haría responsable de establecer el régimen de aceptabilidad en virtud del cual juzgar la pertinencia de sus elaboraciones, de sus estatutos de mundo. Este orden de cosas, promotor de un pluralismo visional, no solo introduce en el tinglado de las versiones de mundo registros de interpretación proscritos por la autarquía de la ciencia moderna; permite, además, equiparar, sin restricciones, el proceder del artista con el quehacer del científico, o el religioso, artesanos los tres de realidad. 
Advirtamos cómo esta perspectiva filosófica del giro estético, que reúne construccionistas, pos-analíticos, pos-modernos, etc., reconoce como análogos, en el sentido de versiones posibles, registros no exclusivamente veritativos como el de la epistemología, habituada como está a la lógica de la demostración y a la autoridad del argumento. Tanto es así que sin rubor yuxtapone a la versión ciencia, la versión arte, señalando que las dos refieren realidades que podrían perfectamente catalogarse de ficcionales, pues, cada cual produce "fantasías" mediante las cuales los sujetos operamos. O, ¿qué vendría a ser un átomo sino, según Bachelard (1948), un puñado de argumentos hecho con base en la misma materia prima con la que fueron creados Don Quijote o Madame Bovary?

Metáforas todas mediante las cuales nos conducimos a través de la imagen que hemos construido de mundo. Y ya el acceso a sus secretos más recónditos no sería para el giro estético lo imprescindible; su pretensión será otra: la de propender por el reconocimiento de otras maneras de "versionar" la realidad que añadan, además de los dualismos y simplificaciones lógicas que esgrimen, cada vez menos sin embargo, las ciencias duras, otros modos de a-prender la realidad que permitan significar órdenes distintos de relacionamiento al mundo; modalidades que, absueltas del mote peyorativo de "irreales", susciten comprensiones renovadas, capaces de instituir realidad, como la ciencia, que a veces cree hacerlo mejor que otras instancias a las que tilda socarronamente de productoras de fantasía.

Con lo anterior no busco irme lanza en ristre, como lo advertí en la introducción, contra el paradigma cientista del que, de un modo u otro, somos hijos. La intención, al exponer muy grosso modo los principios del giro estético, ha sido más bien la de buscar establecer distancia respecto de la actitud sacra con la que nos acercamos a la ciencia, imbuidos por un dogmatismo que, a lo largo de los siglos, hemos naturalizado a fuerza de seguirlo devotamente.

Así pues, esa idea de arrogarle solo al campo lógico-formal, adoptado por la ciencia, el cometido de signar nuestra relación con el conocimiento y la vida, a expensas de otros campos igual de sugestivos y potentes, le resulta al giro estético sumamente devaluada. Por ello acoge el pluralismo como alternativa paradigmática de conocimiento y racionalidad, basado en una filosofía reacia al fundamento cuya naturaleza, de concedérsela, sería ficcional y elaborada, nunca absoluta. Premisas de tal envergadura, de corte abiertamente relativista, circunscriben el giro estético más a un plano éticopolítico que epistémico, pues, en este último, por tradición, lo que suele privilegiarse es la verdad, aquella inmaculada, prístina, incontrovertible y única a la que la racionalidad moderna quiso plegarnos. Y bajo ese régimen las tesis relativistas que oxigenan el giro estético no resultarían del todo plausibles, pues serían presa fácil del escrutinio platónico ideado por Occidente.

De allí que no quepa valorar el giro del cual hablamos desde la gramática distintiva de la lógica de la demostración y la comprobación, a la que, en buena medida, se renuncia en virtud de atender a otras esferas, distintas de aquellas asociadas a la búsqueda de la verdad y el conocimiento claro y distinto. Hablamos pues de prácticas fomentadoras de vínculos irreductibles al ámbito de la racionalidad, como las narrativas, que auspician dimensiones de índole plural, filiales de la ética, la política y el arte en tanto reivindican el valor, la acción y la sensación como instancias no marginales sino instituyentes de realidad.

De este modo, el giro estético nos confiere un ángulo de mirada que le resta privilegios al método científico como garante expedito del arca de la verdad. Su filosofía empuja a la ciencia a poner de relieve su carácter situacional, elaborado e intencional, tornándola en consecuencia, una creación humana más, a la altura de otras muchas respecto de las cuales no podría blandir credencial alguna de autenticidad fundamentada que le pusiese por encima de las demás. Nos topamos por tanto con un planteamiento, me refiero al giro, capaz de congregar ficción y realidad en función de servir a la "ampliación, reconstrucción y recreación permanente de la experiencia de mundo" (Bermejo, 2008, p. 82). 


\section{Referencias bibliográficas}

Bachelard, G. (1948).La formación del espíritu científico. México: Siglo xxI, 1979.

Bermejo, D. (2008). Estetización epistemológica. En las fronteras de la ciencia (pp.51-82). Barcelona: Anthropos.

Bermejo, D. (2008). La construcción de realidad. La realidad de la ficción y la ficciónde la realidad. En las fronteras de la ciencia (pp. 11-49). Barcelona: Anthropos.

Ibáñez, T. (2002). Municiones para disidentes. Realidadverdad-política. España: Gedisa.

Cruz Kronfly, F. (2007). El declive del pensamiento crítico y de la cultura su impacto en la práctica social: la educación como espacio de resistencia cultural. Observatorio Pedagógico de Medios, 15.

Gibson-Grahama, J. (2002). El posestructuralismo. Revista Colombiana de Antropología, 38, 261-285.

Hamui Sutton, S. (2014). La lectura como escritura: una mirada de Borges desde Derrida. Enunciación, 19(1).

Taylor, Ch. (1997). Argumentos filosóficos. Ensayos sobre el conocimiento, el lenguaje y la modernidad. Barcelona: Paidós. 